\title{
NeUrobiology of Eye Movement DesensitizATION AND REPROCESSING
}

\author{
Hana Vojtova ${ }^{1,2^{*}}$, Jozef Hasto ${ }^{2}$ \\ ${ }^{l}$ Center for Neuropsychiatric Research of Traumatic Stress \& Department of Psychiatry, First Faculty of Medicine, \\ Charles University, Prague, Czech Republic \\ ${ }^{2}$ Department of Psychiatry, Faculty Hospital, Trencin, Slovak Republic \\ Received June 21, 2009; accepted September 2, 2009
}

\begin{abstract}
Eye Movement Desensitization and Reprocessing represents a promising approach to treatment of posttraumatic disorders. The specific factors underlying its effectiveness rely particularly on bilateral stimulation, which seems to provoke a specific neurobiological response during traumatic recall particularly in individuals with PTSD. The empirical findings provide evidence for the effect of BLS on autonomic nervous system shifting the balance towards parasympathetic activation (reducing arousal) as well as the effect on subjectively perceived vividness and emotional burden of autobiographic memories (decrease). The most credible hypotheses derive the effects from neurobiological mechanisms employed in dual focus attention, orienting reflex and REM sleep. Further research is needed to explore the processes included in the EMDR therapy in more detail and clarify the role of bilateral stimulation.
\end{abstract}

Key words: Brain; Dissociation; Eye movement desensitization and reprocessing; Posttraumatic stress disorder; Psychotherapy

\section{INTRODUCTION}

Eye Movement Desensitization and Reprocessing (EMDR) is a structured treatment method integrating effective components of various psychotherapeutic approaches (cognitive, behavioral, psychodynamic, hypnotherapy etc.) with bilateral stimulation. Bilateral stimulation (BLS) contains elementary sensory stimuli that alternately activate left-right hemisphere through visual, tactile or auditory modalities (Shapiro \& Maxfield, 2002). BLS is mainly used in specific phases of treatment related to recall of traumatic memory, when re-processing of information and memory modification is needed for further progress of the therapy. Recent findings suggest that EMDR and its specific components related to BLS might engage a specific neurobiological mechanism that could be substantially responsible for its efficiency.

\section{POSTTRAUMATIC STRESS DISORDER AND TRAUMATIC MEMORIES}

Most apparent symptoms that occur in PTSD are recurrent extremely vivid recollections of traumatic expe- rience (intrusions) that are frequently related to partial or complete amnesia and decrease of affective control. Typical manifestations of PTSD present extreme level of arousal linked to a specific pattern of neural activity that is repeatedly triggered during every traumatic recall (van der Kolk, 2004). Crucial neurobiological changes related to this process present activation of the hippocampus and the amygdala together with deactivations in prefrontal cortex (Rauch et al., 2006) reflecting a shift into diverse mode of memory encoding (Diamond et al., 2007). This atypical mode of memory encoding likely could explain disintegrated nature of traumatic memories with typical deficits in temporal and semantic context known as dissociation. According to recent findings dissociation may play a key role in pathogenesis of posttraumatic disorder (van der Kolk, 1996; Bryant, 2007; Nijenhuis et al., 2004; van der Hart et al., 2005). Within this context, psychotherapy of PTSD mainly aims at integration and modification of traumatic memories and facilitating new learning. On the other hand unsuccessful therapy may cause re-traumatization and strengthening of traumatic memory.

\footnotetext{
*Correspondence to: Hana Vojtova, e-mail: hanavojtova@seznam.cz
} 


\section{EMDR AND BILATERAL STIMULATION (BLS)} A specific feature of EMDR therapy is BLS. Bilateral stimulation in general includes elementary sensory stimuli that alternately elicit left and right hemispheric activity through visual, tactile or auditory modalities. In a typical clinical setting the most frequent procedure is visual stimulation that is performed by a therapist using a finger that moves back and forth along a horizontal line about $50 \mathrm{~cm}$ in front of the patient's face that produces saccadic or pursuit eye movements (Shapiro, 2001). The visual stimulation is the best known procedure of BLS but there are also methods using other types of stimulation such as tactile or auditory stimuli bilaterally alternating with relatively regular rhythms (approximately 0,5-2Hz) (Shapiro, 2001). Although BLS may be applied in various sensory modalities, majority of recent studies were focused on eye movements (Davidson \& Parker, 2001). In summary, recent findings suggest that several procedural elements of EMDR such as selection of treatment targets, mindfulness-like attitude, alignment of memory fragments, somatic awareness, cognitive restructuring and perceived mastery, induced by its specific therapeutic procedure contribute to therapeutic effectiveness (Solomon \& Shapiro, 2008).

\section{EMDR AND AROUSAL}

The majority of studies focusing on influence of EMDR on physiology compared pre- and post- values of physiological measures (Dunn et al., 1996; Montgomery \& Ayllon, 1994), only a few recorded them during engagement in BLS (Wilson et al., 1996). These studies relatively consistently show dearousal effect of BLS, through activating parasympathetic cholinergic system while inhibiting the sympathetic system (Wilson et al., 1996; Barrowcliff, 2003, 2004; Sack et al., 2008a,b; Elofsson et al., 2007). At onset of the stimulation, a sharp increase of heart rate variability and a significant decrease of heart rate can be observed (Sack et al., 2008a) as well as the decrease of skin conductance level, increase of skin temperature and a changed balance between high frequency and low frequency heart rate variability (Elofsson et al., 2007). During ongoing stimulation, the stress-related arousal increases but remains on a rather lower level and there is a marked trend to significant decrease of psycho-physiological activity across entire sessions. Interestingly, Kreyer (2008) in her very thoroughly conducted study found that significant relaxation response is released in eye movements $(1 \mathrm{~Hz}$ and $0,3 \mathrm{~Hz})$ as well as in eyes fixed condition.

These findings indicate that although the retrieval of traumatic memory leads to elevation of cardiovascular action that is supposed to hinder processing of information in central nervous system, after application of EMDR stimulation, immediate shift in heart rate is prompted with subsequent increase of heart rate variability accompanying parasympathetic dominance (Kreyer, 2008). According to recent findings the cardiovascular modulation via vagal influence relies mainly on ventromedial prefrontal cortex and amygdalahippocampal complex (Hänsel \& von Känel, 2008; Hilz et al., 2006), which are crucial for neurobiological mechanisms involved in pathophysiology of PTSD (Dickie et al., 2008; Elzinga \& Bremner, 2002; Liberzon et al., 2007).

\section{EMDR AND WORKING MEMORY}

A typical memory reprocessing during EMDR requires an ability of consciousness to integrate several simultaneous modes of information processed in working memory (Maxfield et al., 2008). According to several recent findings BLS loads the capacity of working memory (Gunter \& Bodner, 2008; Kemps \& Tiggemann, 2007; Andrade et al., 1997). BLS in EMDR supports a detached position during reprocessing of traumatic memory (Lee \& Drummond, 2008), which is correlated with improvement in symptoms (Lee et al., 2006). This finding is in agreement with results of research studies focused on impact of eye movements on image vividness and emotional intensity of autobiographic memories. This research indicates that eye movements reduce the vividness and emotional valence of autobiographical memories (Sharpley et al., 1996a; Kavanagh et al., 2001; van den Hout et al., 2001; Barrowcliff et al., 2003, 2004; Lee et al., 2007; Kemps \& Tiggemann, 2007; Gunter \& Bodner, 2008).

\section{EMDR AND ORIENTING REFLEX}

The orienting reflex (OR) hypothesis about EMDR mechanism of action postulates that the role of stimulation in the procedure is to elicit OR, which in turn triggers changes in activity of central and autonomic nervous system (MacCullogh \& Feldman, 1996; Armstrong \& Vaughan, 1996). In general, OR is assumed to enable new information to be noticed and integrated into consciousness, which may cause specific changes in neuronal activity and plasticity (Kaye, 2007). In this context, several interrelationships can be observed in OR and in EMDR (Hekmat et al., 1994; Armstrong \& Vaughan, 1996; Kaye, 2007). For example, during OR and EMDR perception of painful stimuli is decreased, which is frequently linked to parasympathetic dearousal effect (Hekmat et al., 1994; Armstrong \& Vaughan, 1996). These findings are in agreement with results obtained by analysis of event-related potentials in PTSD patients undergoing EMDR treatment, which have shown post-session attenuation of $\mathrm{P} 3 \mathrm{a}$ component representing a correlate of $\mathrm{OR}$ related to automatic orientation of attention towards a source of stimulation (Lamprecht et al., 2004). Several lines of evidence also shows that these attentional alterations may be neuro- 
chemically based on decreased noradrenergic activity mediated by inhibitory effects on the locus coeruleus, which also emerges during rapid eye movements REM sleep dream activity (Kuiken et al., 2002; Missonier et al., 1999).

\section{EMDR AND REM SLEEP}

Above reported similarities between eye movements used in the original EMDR procedure and REM sleep have lead to hypothesis that both processes share common neurobiological mechanisms. This hypothesis is also in agreement with findings that PTSD sleep cycle is significantly impaired and reduction of REM sleep presents a typical symptom of PTSD. In addition, REM sleep plays an important role in processing of emotional memories and also memories related to traumatic experiences (Bob, 2004; Wagner \& Born, 2008, Silvestri \& Root, 2008).

In general, sleep plays crucial role in natural, automatic information processing and memory consolidation without any demands on voluntary control. This includes analysis and synthesis of both old and new information and may produce enhanced declarative memories as well as new implicit insights (Stickgold, 2008). These effects are strikingly similar to the outcome of EMDR treatment. In this context, Stickgold (2002) hypothesizes common neurobiological background of EMDR and REM sleep. During REM sleep information flow from neocortex to hippocampus is enhanced while transfer in the opposite direction is inhibited and neocortical, semantic (in contrast to hippocampal, episodic) memories are strenghtened. This preference of activity in cortical semantic networks favors weaker, more distant associations to stronger ones, which might explain the hyperassociative nature of dreams and could underlie the loosening of restricted associative chain seen in EMDR.

\section{CONCLUSION}

In summary recent findings indicate that Eye Movement Desensitization and Reprocessing represents a promising approach to treatment of posttraumatic disorders (van der Kolk et al., 2007; Bisson \& Andrew, 2007; Bisson et al. 2007; Foa et al., 2000; van Etten \& Taylor, 1998). The specific factors underlying its effectiveness rely particularly on bilateral stimulation, which seems to provoke a specific neurobiological response during traumatic recall particularly in individuals with PTSD. During the reliving of traumatic experience in PTSD, the psychophysiological arousal increases and attention is narrowly focused on reliving the traumatic experience without appropriate correction. At this point EMDR is a suitable method that provides down-regulation of excessive arousal which enables to prepare the central nervous system for refocusing of attention and a new learning. From the ethological perspective the new learning is related to activation of the seeking action system as defined by Panksepp, which comprises explorative and appetitive behavior (Panksepp, 1998; Alcaro et al., 2007). The seeking system depends on dopaminergic system of lateral hypothalamus, ventral tegmental area and nucleus accumbens, and is closely connected to memory circuits of hippocampus as well as reward cortical circuits. The activation of the seeking system during psychotherapy is likely responsible for the refocusing of attention towards a new information and its incorporation and integration into existing memory networks. On the other hand down-regulation of excessive arousal (Cozolino, 2006; Schore, 2003) is likely achieved by BLS and creation of the safe context of the therapeutic setting (Bowlby, 1969; Hasto, 2005) that presents a radical contrast to the traumatic threat with influence on psychophysiological and neurobiological functioning of the traumatized individual (van der Hart, Nijenhuis \& Steele, 2006).

\section{REFERENCES}

Alcaro, A., Huber, R., \& Panksepp J. (2007). Behavioral functions of the mesolimbic dopaminergic system: an affective neuroethological perspective. Brain research reviews, 56, 283-321.

Andrade, J., Kavanagh, D., \& Baddeley, A. (1997). Eyemovements and visual imagery: A working memory approach to the treatment of post-traumatic stress disorder. British Journal of Clinical Psychology, 36, 209-223.

Armstrong, M.S. \& Vaughan, K. (1996). An orienting response model of Eye Movement Desensitisation. Journal of Behaviour Therapy and Experimental Psychiatry, 27, 21-32.

Barrowcliff, A.L., Gray, N.S., Freeeman, T.C.A., \& MacCulloch, M.J. (2004). Eye-movements reduce the vividness, emotional valence and electrodermal arousal associated with negative autobiographical memories. Journal of Forensic Psychiatry \& Psychology, 15, 325-345.

Barrowcliff, A.L., Gray, N.S., MacCulloch, S., Freeman, T.C.A., \& MacCulloch, M.J. (2003). Horizontal rhythmical eye-movements consistently diminish the arousal provoked by auditory stimuli. British Journal of Clinical Psychology, 42, 289-302.

Bisson, J. \& Andrew M. ( 2007). Psychological treatment of post-traumatic stress disorder (PTSD). Cochrane Database of Systematic Reviews, Issue 2, Art. No.: CD003388. DOI: 10.1002/14651858.CD003388.pub3

Bisson, J.I., Ehlers, A., Matthews, R., Pilling, S., Richards, D., \& Turner, S. (2007). Psychological treatments for chronic post-traumatic stress disorder: Systematic review and metaanalysis. The British Journal of Psychiatry, 190, 97-104.

Bob, P. (2004). Dissociative processes, multiple personality and dream functions. American Journal of Psychotherapy, 58, 139-149.

Bowlby, J. (1969). Attachment and loss: Attachment. New York: Basic.

Bryant, R.A. (2007). Does dissociation further our understanding of PTSD? Journal of Anxiety Disorders, 21, 183-191.

Cozolino, L. (2006). The neuroscience of human relationships: attachment and the developing social brain. New York, London: Norton. 
Davidson P.R., \& Parker K.C. (2001). Eye movement desensitization and reprocessing (EMDR): A meta-analysis. Journal of consulting and clinical psychology, 69, 305-16.

Diamond D.M., Campbell A.M., Park C.R., Halonen J., \& Zoladz P.R. (2007). The temporal dynamics model of emotional memory processing: A synthesis on the neurobiological basis of Stress-induced amnesia, flashbulb and traumatic memories, and the Yerkes-Dodson law. Neural Plasticity, Article ID 60803, 33pp, doi:10.1155/2007/60803.

Dickie E.W., Brunet A., Akerib V., \& Armony J.L. (2008). An fMRI investigation of memory encoding in PTSD: influence of symptom severity. Neuropsychologia, 46, 15221531.

Dunn et al. (1996). Measuring the effectiveness of Eye Movement Desensitization and Reprocessing (EMDR) in nonclinical anxiety: a multisubject yoked-control design. Journal of Behavior Therapy and Experimental Psychiatry, 27, 231239.

Elofsson, U.O.E., von Schèele, B., Theorell, T., \& Söndergaard, H.P. (2007). Physiological correlates of eye movement desensitization and reprocessing. Journal of Anxiety Disorders, 22, 622-634.

Elzinga B.M., \& Bremner J.D. (2002). Are the neural substrates of memory the final common pathway in posttraumatic stress disorder (PTSD)? Journal of Affective Disorders, 70, 1 17.

Foa, E.B., Keane, T.M., \& Friedman, M.J. (2000). Effective treatments for PTSD: Practice guidelines of the International Society for Taumatic Stress Studies. New York: Guilford Press.

Gunter R.W., \& Bodner G.E. (2008). How eye movements affect unpleasant memories: Support for a working-memory account. Behaviour Research and Therapy, 46, 913-931.

Hasto, J. (2005). Vztahova vazba. Ku korenom lasky a uzkosti. Trencin: Vydavatelstvo F.

Hänsel, A., \& von Känel, R. (2008). The ventro-medial prefrontal cortex: a major link between the autonomic nervous system, regulation of emotion, and stress reactivity?. BioPsychoSocial Medicine, 2, 21.

Hekmat, H., Groth, S. \& Rogers, D. (1994). Pain ameliorating effects of Eye Movement Desensitization. Journal of Behavior Therapy and Experimental Psychiatry, 25, 121-129.

Hilz, M.J., Devinsky, O., Szczepanska, H., Borod, J. C., Marthol, H., \& Tutaj, M. (2006). Right ventromedial prefrontal lesions result in paradoxical cardiovascular activation with emotional stimuli. Brain, 129, 3343-3355.

Kavanagh, D.J., Freese, S., Andrade, J., \& May, J. (2001). Effects of visuospatial tasks on desensitization to emotive memories. British Journal of Clinical Psychology, 40, 267280.

Kaye, B. (2007). Reversing reciprocal suppression in the anterior cingulate cortex: A hypothetical model to explain EMDR effectiveness. Journal of EMDR Practice and Research, 1, 8899.

Kemps E., \& Tiggemann M. (2007). Reducing the vividness and emotional impact of distressing autobiographical memories: The importance of modality-specific interference. Memo$r y, 15,412-422$.

Kreyer, A.-K. (2008). Experimentelle Überprüfung psychophysiologischer Prozesse im EMDR (Eye Movement Desensitization and Reprocessing). Inauguraldissertation. Köln: Uni- versität zu Köln. URN: urn:nbn:de:hbz:38-24346. URL: http://kups.ub.uni-koeln.de/volltexte/2008/2434/.

Kuiken, D., Bears, M., Miall, D. \& Smith, L. (2002). Eye Movement Desensitization Reprocessing facilitates attentional orienting. Imagination, Cognition and Personality, 21, 3-20.

Lamprecht, F., Kohnke, C., Lempa, W., Sack, M., Matzke, M. \& Munte, T.F. (2004). Eventrelated potentials and EMDR treatment of post-traumatic stress disorder. Neuroscience Research, 49, 267-72.

Lee, C.W., \& Drummond, P.D. (2008). Effects of eye movement versus therapist instructions on the processing of distressing memories. Journal of Anxiety Disorders, 22, 801-808.

Lee, C.W., Taylor, G., \& Drummond, P. (2006). The active ingredient in EMDR: is it traditional exposure or dual focus attention? Clinical Psychology \& Psychotherapy, 13, 97-107. Liberzon I., King A.P., Britton J.C., Phan K.L., Abelson J.L., \& Taylor S.F. (2007). Paralimbic and medial prefrontal cortical involvement in neuroendocrine responses to traumatic stimuli. The American Journal of Psychiatry, 164, 1250-1258. MacCulloch, M.J. \& Feldman P. (1996). Eye Movement Desensitisation Treatment utilises the positive viscereal element of the investigatory reflex to inhibit the memories of posttraumatic stress disorder: a theoretical analysis. British Journal of Psychiatry. 169, 571-579.

Maxfield L., Melnyk W.T. \& Hayman G.C.A. (2008). A working memory explanation for the effects of eye movements in EMDR. Journal of EMDR Practice and Research, 2, 247-261. Missonnier, P., Ragot, R., Derouesné, C., Guez, D., \& Renault, B. ( 1999). Automatic attentional shifts induced by a noradrenergic drug in Alzheimer's disease: evidence from evoked potentials. International Journal of Psychophysiology, 33, 243-251.

Montgomery R.W., \& Ayllon T. (1994). Eye Movement Desensitization across subjects: Subjective and physiological measures of treatment efficacy. Journal of Behavior Therapy and Experimental Psychiatry, 25, 217-230.

Nijenhuis, E.R., van der Hart, O., Kruger, K., Steele, K. (2004). Somatoform dissociation, reported abuse and animal defence-like reactions. The Australian and New Zealand Journal of Psychiatry, 38, 678-686.

Panksepp, J. (1998). Affective neuroscience: The foundation of human and animal emotions. New York: Oxford University Press.

Rauch S.L, Shin L.M., \& Phelps E.A. (2006). Neurocircuitry models of posttraumatic stress disorder and extinction: human neuroimaging research - past, present, and future. Biological Psychiatry, 60, 376-382.

Sack, M., Lempa, W., Steinmetz, A. Lamprecht, F., \& Hofmann, A. (2008a). Alterations in autonomic tone during trauma exposure using Eye Movement Desensitization and Reprocessing (EMDR) - results of a preliminary investigation. Journal of Anxiety Disorders, 22, 1264-1271.

Sack, M., Hofmann, A.,Wizelman L., \& Lempa W. (2008b). Psychophysiological changes during EMDR and treatment outcome. Journal of EMDR Practice and Research, 2, 239246.

Schore, A. (2003). Affect disregulation and disorders of the self. New York, London: Norton.

Shapiro, F. (2001). Eye Movement Desensitization and Reprocessing (EMDR): Basic principles, protocols, and procedures. New York: The Guilford Press. 
Shapiro F., \& Maxfield L. (2002). Eye movement desensitization and reprocessing (EMDR): Information Processing in the treatment of trauma. Journal of Clinical Psychology, 58, 933-946.

Sharpley, C.F., Montgomery, I.M. \& Scalzo, L.A. (1996a). Comparative efficacy of EMDR and alternative procedures in reducing the vividness of mental images. Scandinavian Journal of Behaviour Therapy, 25, 37-42.

Silvestri, A.J. \& Root, D.H. (2008). Effects of REM deprivation and an NMDA agonist on the extinction of conditioned fear. Physiology \& Behavior, 28, 274-81.

Solomon, R.M. \& Shapiro, F. (2008). EMDR and the Adaptive information processing model. Journal of EMDR Practice and Research, 2, 315-325.

Stickgold, R. (2008). Sleep-Dependent Memory Processing. Journal of EMDR Practice and Research, 2, 289-299.

Stickgold, R. (2002). EMDR: a putative neurobiological mechanism of action. Journal of Clinical Psychology, 58, 61-75. van den Hout, M., Muris, P., Salemink, E., \& Kindt, M. (2001). Autobiographical memories become less vivid and emotional after eye movements. British Journal of Clinical Psychology, 40, 121-130.

van der Hart, O., Nijenhuis, E.R., \& Steele, K. (2005). Dissociation: An insufficiently recognized major feature of complex posttraumatic stress disorder. Journal of Traumatic Stress, 18, 413-423.

van der Hart, O., Nijenhuis, E.R., \& Steele, K. (2006). The haunted self. Structural dissociation and the treatment of chronic traumatization. New York, London: Norton.

van der Kolk B.A. (1996). Trauma and Memory. In: van der van Kolk B.A., McFarlane, A.C., \& Weisaeth L. (Eds.), Traumatic stress. The effects of overwhelming experience on mind, body, and society, pp. 279-303. New York, London: The Guilford Press.

van der Kolk B.A. (2004). Psychobiology of posttraumatic stress disorder. In: Panksepp J. (Ed.), Textbook of clinical psychiatry, pp. 319-344. New York: Wiley.

van der Kolk, B.A., Spinazzola, J., Blaustein, M.E., Hopper, J.W., Hopper, E.K., Korn, D.L., \& Simpson, W.B. (2007). A randomized clinical trial of Eye Movement Desensitization and Reprocessing (EMDR), fluoxetine, and pill placebo in the treatment of posttraumatic stress disorder: treatment effects and long-term maintenance. The Journal of Clinical Psychiat$r y, 68,37-46$.

van Etten, M., \& Taylor, S. (1998). Comparative efficacy of treatments for post-traumatic stress disorder: A meta-analysis. Clinical Psychology and Psychotherapy, 5, 126-144.

Wagner, U. \& Born, J. (2008). Memory consolidation during sleep: interactive effects of sleep stages and HPA regulation. Stress, 11, 28-41.

Wilson, D., Silver, S. M., Covi, W., \& Foster, S. (1996). Eye movement desensitization and reprocessing: Effectiveness and autonomic correlates. Journal of Behavior Therapy and Experimental Psychiatry, 27, 219-229. 